\title{
Letter to the editor regarding article, "Role of glycogen synthase kinase following myocardial infarction and ischemia-reperfusion"
}

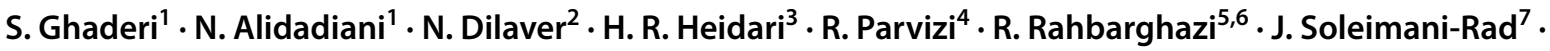 \\ B. Baradaran ${ }^{8}$ (i)
}

Published online: 11 May 2019

(c) Springer Science+Business Media, LLC, part of Springer Nature 2019

Dear editor and Zhi-Qing Chen et al.,

We humbly write to thank Zhi-Qing Chen et al. for their letter where they have pointed out the miswritten difference we have reported in molecular structure in our already published paper between GSK-3 $\alpha$ and GSK-3 $\beta 2$ and to express our deepest apologies for this miswritten phrase in our paper [1]. We totally agree with Zhi-Qing Chen et al. that GSK-3 $\alpha$ occupies a domain with 13 amino acids inserts at the N-terminal of GSK-3 $\alpha$ and not GSK-3 $\beta 2$. We correct the sentence in this letter for all readers and the sentence is now "The catalytic domain is highly conserved between the two isoforms. Compared with GSK-3 $\beta 2$, GSK-3 $\alpha$ occupies a domain with a 13 amino acid insert [2] consisting of a glycine-rich domain at the $\mathrm{N}$-terminal."
B. Baradaran

baradaranb@tbzmed.ac.ir

1 Department of Systems Physiology, Ruhr University Bochum, Universitätsstrasse 150, 44790 Bochum, Germany

2 Swansea University Medical School, Swansea University, Swansea, UK

3 Department of Pharmaceutical Biotechnology, Faculty of Pharmacy, Tabriz University of Medical Sciences, Tabriz, Iran

4 Department of Cardiothoracic Surgery, Faculty of Medicine, Tabriz University of Medical Sciences, Tabriz, Iran

\section{References}

1. Ghaderi S, Alidadiani N, Dilaver N, Heidari HR, Parvizi R, Rahbarghazi R, Soleimani-Rad J, Baradaran B (2017) Role of glycogen synthase kinase following myocardial infarction and ischemia-reperfusion. Apoptosis 22(7):887-897. https://doi. org/10.1007/s10495-017-1376-0

2. Wu D, Pan W (2010) GSK3: a multifaceted kinase in Wnt signaling. Trends Biochem Sci 35(3):161-168. https://doi.org/10.1016/j. tibs.2009.10.002

Publisher's Note Springer Nature remains neutral with regard to jurisdictional claims in published maps and institutional affiliations.
5 Stem Cell Research Center, Tabriz University of Medical Sciences, Tabriz, Iran

6 Department of Applied Cell Sciences, Faculty of Advanced Medical Sciences, Tabriz University of Medical Sciences, Tabriz, Iran

7 Department of Anatomy, Faculty of Medicine, Tabriz University, Tabriz, Iran

8 Immunology Research Center, Tabriz University of Medical Sciences, Tabriz, Iran 